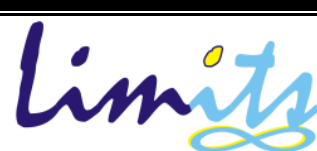

Limits: Journal of Mathematics and Its Applications

E-ISSN: 2579-8936

P-ISSN: 1829-605X

Vol. 17, No. 2, Desember 2020, 157-172

DOI: http://dx.doi.org/10.12962/limits.v17i2.6901

\title{
Analisis Dinamik pada Model Kanker Serviks dengan Vaksinasi dan Screening
}

\author{
Karunia Theda Kristanti ${ }^{1}$ *, Trisilowati $^{2}$, Agus Widodo ${ }^{3}$ \\ 1,2,3 Fakultas Matematika dan Ilmu Pengetahuan Alam, Universitas Brawijaya, Malang, Indonesia \\ e-mail: kristantikarunia@gmail.com
}

Diajukan: 11 Mei 2020, Diperbaiki: 19 Juli 2020, Diterima:27 Juli 2020

\begin{abstract}
Abstrak
Pada paper ini dibahas analisis dinamik model penyebaran kanker serviks dengan melibatkan tindakan vaksinasi dan screening. Penyebab utama terjadinya kanker serviks adalah karena seseorang terinfeksi Human Papillomavirus (HPV). Infeksi ini dapat menular karena adanya kontak langsung melalui hubungan seksual antara subpopulasi wanita rentan dengan pria terinfeksi HPV maupun kontak langsung antara pria rentan dengan wanita terinfeksi HPV. Pada model ini diasumsikan vaksin diberikan pada subpopulasi wanita rentan saja dengan salah satu jenis vaksin. Sementara itu, screening dilakukan oleh subpopulasi wanita terifeksi HPV sebagai upaya deteksi dini untuk mencegah terjadinya kanker serviks. Hasil analisis dinamik menunjukkan bahwa model penyebaran kanker serviks dengan vaksinasi dan screening memiliki dua titik kesetimbangan yaitu titik kesetimbangan bebas penyakit dan titik kesetimbangan endemi. Eksistensi dan kestabilan lokal titik kesetimbangan bergantung pada nilai angka reproduksi dasar $R_{0}$. Berdasarkan hasil analisis, titik kesetimbangan bebas penyakit eksis tanpa syarat, sedangkan titik kesetimbangan endemi eksis jika $R_{0}>1$. Titik kesetimbangan bebas penyakit bersifat stabil asimtotik lokal jika nilai $R_{0}<1$ dan titik kesetimbangan endemi bersifat stabil asimtotik lokal jika memenuhi kriteria Routh-Hurwitz. Simulasi numerik yang dilakukan mendukung hasil analisis dinamik yang diperoleh.
\end{abstract}

Kata Kunci: analisis kestabilan lokal, angka reproduksi dasar, Human Papillomavirus, kanker serviks.

\begin{abstract}
In this paper, the dynamical analysis of cervical cancer model with vaccination and screening is discussed. The leading cause of cervical cancer is because of Human Papillomavirus (HPV). This infection can be transmitted due to direct contact through sexual intercourse between susceptible females with infected males and contact directly between susceptible males with infected females. In this model, it is assumed that vaccination is given to susceptible females with any of various vaccines. Meanwhile, screening is done by infected females with HPV as an early detection to prevent cervical cancer. Dynamical analysis results show that the model has two equilibrium points, namely the disease-free equilibrium point and endemic equilibrium point. The existence and stability of equilibrium points depend on the basic reproduction number $R_{0}$. The disease-free equilibrium point exists unconditionally, while the endemic equilibrium exists when $R_{0}>1$. If $R_{0}<1$, then the disease-free equilibrium point is local asymptomatically stable. The endemic equilibrium point is locally asymptomatically stable if it satisfies the Routh-Hurwitz criteria. The numerical simulation is illustrated to support the analysis result.
\end{abstract}

Keywords: local stability analysis, basic reproduction number, Human Papillomavirus, cervical cancer. 


\section{Pendahuluan}

Kanker serviks adalah kanker leher rahim yang ditandai dengan perubahan sel abnormal dan secara bertahap berkembang menjadi kanker. Penyakit ini dapat dicegah jika terdeteksi lebih awal dan dilakukan tindakan yang tepat, tetapi menjadi penyakit yang mematikan jika terlambat dalam penangannya [1]. Kanker serviks terkonfirmasi $70 \%$ disebabkan oleh infeksi Human Papillomavirus (HPV). Selain itu, penyebab kanker serviks didukung karena hubungan seksual yang dilakukan terlalu dini, usia persalinan pertama yang belum cukup umur, rendahnya pendidikan, dan jumlah pasangan seksual yang berganti-ganti [2].

Vaksinasi dapat dipilih sebagai salah satu cara untuk merangsang sistem kekebalan tubuh dalam memproduksi antibodi sebagai upaya pencegahan terhadap HPV yang dapat menginfeksi sel dalam tubuh. Terdapat tiga jenis vaksin yang dapat digunakan untuk mencegah penyebaran HPV yaitu vaksin bivalen, vaksin quadrivalen, dan vaksin nonavalen [3], ketiga jenis vaksisn ini dapat digunakan secara bersamaan [4]. Pemberian vaksin secara lengkap dibagi dalam tiga kali dosis dalam kurun waktu 6 bulan. Jika pemberian vaksin tidak diberikan dengan lengkap dapat memengaruhi efikasi vaksin dalam mencegah infeksi HPV [5]. Sementara itu, screening bertujuan untuk mencari adanya masalah kesehatan yang mana jika tidak dilakukan dengan benar menjadi tidak efektif. Screening dapat dilakukan dengan tes Papsmear atau IVA. Tes Papsmear merupakan pemeriksaan sitologi pada serviks guna mendeteksi adanya perubahan pada daerah serviks, sedangkan IVA merupakan tes visual menggunakan larutan asam cuka dan iosium lugol pada serviks dan melihat perubahan warna yang terjadi untuk melihat adanya sel yang displasi [6].

Model matematika telah banyak digunakan untuk mendeskripsikan dampak dari vaksinasi dan screening terhadap infeksi HPV yang dapat berakibat kanker serviks. Pada tahun 2006, Elbasha telah menganalisis dampak vaksin quadrivalen terhadap penyebaran HPV dengan mengembangkan model yang membagi populasi menjadi dua yaitu pria dan wanita yang didasarkan pada model SIR (Susceptible-Infected-Recovery)[7]. Penelitian tentang penyebaran HPV dengan vaksinasi semakin berkembang. Majed dan Lounes telah menganalisis penyebaran HPV dengan model SIS (Susceptible-Infected-Susceptible) dengan menerapkan vaksin quadrivalen [8]. Sementara itu, Van de Velde dkk., membandingkan keefektifan vaksin bivalen, quadrivalen, dan nonavalen terhadap upaya pencegahan penyebaran infeksi HPV [9]. Selanjutnya, Malik dkk. (2016) menerapkan kontrol optimal untuk memperoleh strategi pengendalian infeksi HPV dengan ketiga jenis vaksin, dimana vaksinasi hanya diberikan pada populasi wanita [4]. Selain vaksinasi, penyebaran HPV dengan melibatkan screening telah dibahas oleh Saldana dkk., dengan tujuan untuk mengurangi jumlah populasi terinfeksi HPV [10]. 
Model matematika penyebaran HPV dengan melibatkan kanker serviks telah dibahas oleh beberapa peneliti. Hasnawati pada tahun 2017 membentuk model penyebaran kanker serviks dengan melibatkan subpopulasi vaksinasi dan subpopulasi wanita terkena kanker serviks serta subpopulasi wanita sembuh bisa kembali menjadi wanita rentan [11]. Berbeda dengan model milik Puspita 2019 menunjukkan adanya interaksi antara subpopulasi wanita rentan dengan subpopulasi wanita terinfeksi tanpa adanya vaksinasi [12]. Pada model milik puspitasari, subpopulasi wanita terinfeksi dibedakan menjadi subpopulasi wanita terkena kanker serviks dan tidak terkena kanker serviks. Sementara itu, ditahun yang sama Sado membentuk model penyebaran kanker serviks dengan menambahkan kompartemen subpopulasi wanita tervaksin. Model penyebaran kanker serviks pada penelitian ini melibatkan kompartemen wanita dan pria dengan melibatkan subpopulasi penderita kanker serviks. Selain itu, vaksinasi dan screening dipilih sebagai upaya untuk mencegah penyebaran infeksi HPV untuk menekan terjadinya kanker serviks.

\section{Metode Penelitian}

Pada tahap awal penelitian dilakukan konstruksi model kanker serviks dengan adanya tindakan vaksinasi dan screening. Selanjutnya menentukan titik kesetimbangan model yang diperoleh pada saat sistem berada pada keadaan setimbang dengan menentukan syarat eksistensi dari titik kesetimbangan tersebut. Pada tahap berikutnya dilakukan analisis kestabilan titik kesetimbangan model. Penentuan kestabilan diawali dengan linearisasi model yang selanjutnya ditentukan akar-akar persamaan karakterikstik pada sistem linear hampiran yang telah dibentuk. Kestabilan titk kesetimbangan ditentukan menggunakan kriteria Routh-Hourwitz. Pada tahap akhir dilakukan simulasi numerik untuk mengilustrasikan hasil analisis dinamik dengan menggunakan perangkat lunak MATLAB.

\section{Hasil dan Pembahasan}

Pada bagian ini dibahas konstruksi model, penentuan titik kesetimbangan, angka reproduksi dasar, analisis kestabilan lokal, serta simulasi numerik untuk mengilustrasikan hasil analisis yang telah diperoleh.

\subsection{Konstruksi Model}

Model matematika yang dibentuk pada penelitian ini merupakan penyebaran HPV yang dapat menyebabkan kanker serviks pada wanita. Model terdiri dari kompartemen wanita dan kompartemen pria. Infeksi HPV terjadi karena adanya hubungan seksual atau interaksi antara subpopulasi wanita rentan dengan subpopulasi pria terinfeksi HPV demikian pula sebaliknya. 
Vaksinasi diberikan pada subpopulasi wanita rentan, tetapi hal ini tidak menutup kemungkinan wanita yang sudah divaksin dapat terinfeksi HPV. Wanita aktif secara seksual memiliki peluang yang tinggi terinfeksi HPV, oleh karena itu screening dapat dilakukan untuk mengetahui ada tidaknya sel abnormal yang memiliki peluang kanker serviks. Sementara itu, wanita terinfeksi HPV yang tidak melakukan screening akan memiliki peluang lebih tinggi terkena kanker serviks karena tidak adanya perlindungan maupun pengobatan yang dilakukan. Infeksi HPV yang terjadi baik pada subpopulasi wanita dan pria dapat disembuhkan dengan tindakan pengobatan. Berikut adalah diagram kompartemen yang menggambarkan penyebaran HPV pada pria dan wanita yang aktif secara seksual sampai terjadinya kanker serviks pada subpopulasi wanita.
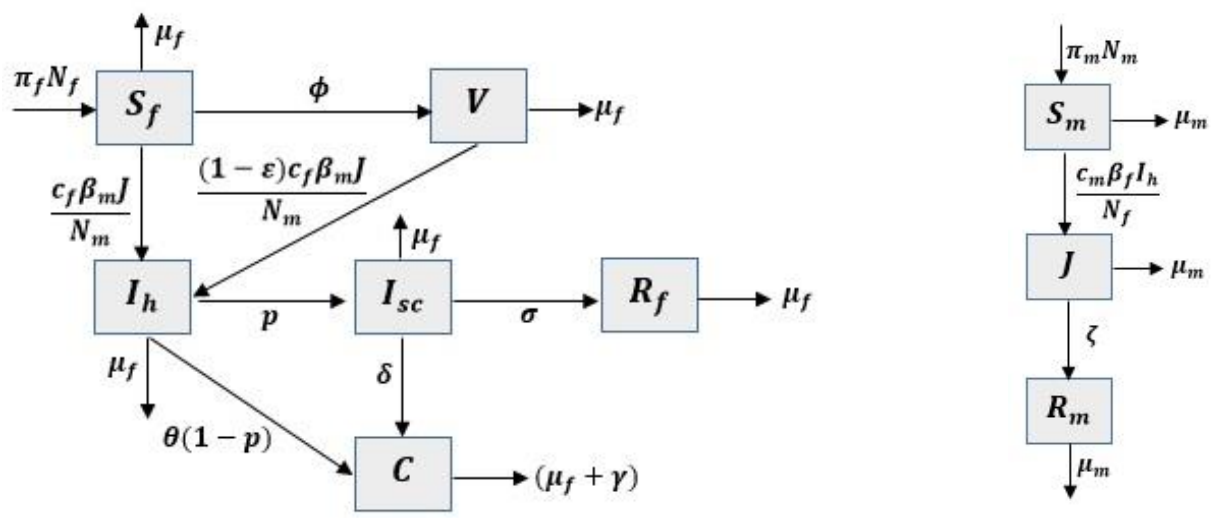

Gambar 1. Diagram kompartemen model penyebaran kanker serviks

Berdasarkan diagram kompartemen pada Gambar 1, model penyebaran kanker serviks dapat dituliskan dalam bentuk persamaan diferensial sebagai berikut.

$$
\begin{aligned}
& \frac{d S_{f}(t)}{d t}=\pi_{f} N_{f}(t)-\phi S_{f}(t)-\frac{c_{f} \beta_{m} J(t) S_{f}(t)}{N_{m}(t)}-\mu_{f} S_{f}(t), \\
& \frac{d V(t)}{d t}=\phi S_{f}(t)-\mu_{f} V(t)-(1-\varepsilon) \frac{c_{f} \beta_{m} J(t) V(t)}{N_{m}} \\
& \frac{d I_{h}(t)}{d t}=\frac{c_{f} \beta_{m} J(t) S_{f}(t)}{N_{m}(t)}+(1-\varepsilon) \frac{c_{f} \beta_{m} J(t) V(t)}{N_{m}(t)}-p I_{h}(t)-\mu_{f} I_{h}(t)-\theta(1-p) I_{h}(t), \\
& \frac{d I_{s c}(t)}{d t}=p I_{h}(t)-\sigma I_{s c}(t)-\mu_{f} I_{s c}(t)-\delta I_{s c}(t), \\
& \frac{d C(t)}{d t}=\delta I_{s c}(t)+\theta(1-p) I_{h}(t)-\left(\mu_{f}+\gamma\right) C(t), \\
& \frac{d R_{f}(t)}{d t}=\sigma I_{s c}(t)-\mu_{f} R_{f}(t) \\
& \frac{d S_{m}(t)}{d t}=\pi_{m} N_{m}(t)-\frac{c_{m} \beta_{f} I_{h}(t) S_{m}(t)}{N_{f}(t)}-\mu_{m} S_{m}(t)+\alpha R_{m}(t),
\end{aligned}
$$


$\frac{d J(t)}{d t}=\frac{c_{m} \beta_{f} I_{h}(t) S_{m}(t)}{N_{f}(t)}-\zeta J(t)-\mu_{m} J(t)$

$\frac{d R_{m}(t)}{d t}=\zeta J(t)-\mu_{m} R_{m}(t)$

dengan

$N_{f}(t)=S_{f}(t)+V(t)+I_{h}(t)+I_{s c}(t)+C(t)+R_{f}(t)$, dan $N_{m}(t)=S_{m}(t)+J(t)+R_{m}(t)$.

Parameter yang digunakan pada model diuraikan pada Tabel 1 sebagai berikut.

Tabel 1. Nilai Parameter

\begin{tabular}{cl}
\hline Parameter & \multicolumn{1}{c}{ Deskripsi } \\
\hline$\pi_{f}\left(\pi_{m}\right)$ & Laju populasi wanita (pria) aktif secara seksual \\
$\mu_{f}\left(\mu_{m}\right)$ & Kematian alami wanita (pria) \\
$\beta_{f}\left(\beta_{m}\right)$ & Peluang infeksi berpindah dari wanita ke pria (pria ke wanita) \\
$c_{f}\left(c_{m}\right)$ & Rata-rata banyaknya kontak seksual \\
$\phi$ & Tingkat vaksinasi \\
$\varepsilon$ & Efikasi Vaksin \\
$p$ & Laju Screening \\
$\theta$ & Laju wanita terinfeksi HPV terkena kanker serviks \\
$\sigma$ & Tingkat populasi wanita sembuh \\
$\zeta$ & Tingkat populasi pria sembuh \\
$\delta$ & Laju subpopulasi wanita screening yang terkena kanker \\
& serviks \\
$\gamma$ & Laju kematian karena kanker serviks \\
\hline
\end{tabular}

Sistem persamaan (1) dapat disederhanakan dengan melakukan penskalaan. Misalkan,

$\bar{S}_{f}(t)=\frac{S_{f}(t)}{N_{f}(t)}, \bar{V}(t)=\frac{V(t)}{N_{f}(t)}, \bar{I}_{h}(t)=\frac{I_{h}(t)}{N_{f}(t)}, \bar{I}_{s c}(t)=\frac{I_{s c}(t)}{N_{f}(t)}, \bar{C}(t)=\frac{C(t)}{N_{f}(t)}$,

$\bar{R}_{f}(t)=\frac{R_{f}(t)}{N_{f}(t)}, \bar{S}_{m}(t)=\frac{S_{m}(t)}{N_{m}(t)}, \bar{J}(t)=\frac{J(t)}{N_{m}(t)}, \bar{R}_{m}(t)=\frac{R_{m}(t)}{N_{m}(t)}$.

Hasil penskalaan di atas sebagai berikut.

$\frac{d \bar{S}_{f}(t)}{d t}=\pi_{f}-\phi \bar{S}_{f}(t)-c_{f} \beta_{m} \bar{J}(t) \bar{S}_{f}(t)-\pi_{f} \bar{S}_{f}(t)$,

$\frac{d \bar{V}(t)}{d t}=\phi \bar{S}_{f}(t)-(1-\varepsilon) c_{f} \beta_{m} \bar{J}(t) \bar{V}(t)-\pi_{f} \bar{V}(t)$,

$\frac{d \bar{I}_{h}(t)}{d t}=c_{f} \beta_{m} \bar{J}(t) \bar{S}_{f}(t)+(1-\varepsilon) c_{f} \beta_{m} \bar{J}(t) \bar{V}(t)-p \bar{I}_{h}(t)-\theta(1-p) \bar{I}_{h}(t)-\pi_{f} \bar{I}_{h}(t)$

$\frac{d \bar{I}_{s c}(t)}{d t}=p \bar{I}_{h}-\sigma \bar{I}_{s c}(t)-\delta \bar{I}_{s c}(t)-\pi_{f} \bar{I}_{s c}(t)$,

$\frac{d \bar{C}(t)}{d t}=\delta \bar{I}_{s c}(t)+\theta(1-p) \bar{I}_{h}(t)-\gamma \bar{C}(t)-\pi_{f} \bar{C}(t)$,

$\frac{d \bar{R}_{f}(t)}{d t}=\sigma \bar{I}_{s c}(t)-\pi_{f} \bar{R}_{f}(t)$ 


$$
\begin{aligned}
& \frac{d \bar{S}_{m}(t)}{d t}=\pi_{m}-c_{m} \beta_{f} \bar{I}_{h}(t) \bar{S}_{m}(t)-\pi_{m} \bar{S}_{m}(t), \\
& \frac{d \bar{J}(t)}{d t}=c_{m} \beta_{f} \bar{I}_{h}(t) \bar{S}_{m}(t)-\zeta \bar{J}(t)-\pi_{m} \bar{J}(t), \\
& \frac{d \bar{R}_{m}(t)}{d t}=\zeta \bar{J}(t)-\pi_{m} \bar{R}_{m}(t) .
\end{aligned}
$$

Berdasarkan sistem (2) tampak bahwa $\bar{R}_{f}(t)$ dan $\bar{R}_{m}(t)$ tidak terlibat di dalam persamaan yang lain, sehingga sistem (2) dapat direduksi untuk memudahkan dalam analisis. Berikut adalah sistem persamaan hasil reduksi.

$$
\begin{aligned}
& \frac{d \bar{S}_{f}(t)}{d t}=\pi_{f}-\phi \bar{S}_{f}(t)-c_{f} \beta_{m} \bar{J}(t) \bar{S}_{f}(t)-\pi_{f} \bar{S}_{f}(t) \\
& \frac{d \bar{V}(t)}{d t}=\phi \bar{S}_{f}(t)-(1-\varepsilon) c_{f} \beta_{m} \bar{J}(t) \bar{V}(t)-\pi_{f} \bar{V}(t) \\
& \frac{d \bar{I}_{h}(t)}{d t}=c_{f} \beta_{m} \bar{J}(t) \bar{S}_{f}(t)+(1-\varepsilon) c_{f} \beta_{m} \bar{J}(t) \bar{V}(t)-p \bar{I}_{h}(t)-\theta(1-p) \bar{I}_{h}(t)-\pi_{f} \bar{I}_{h}(t), \\
& \frac{d \bar{I}_{s c}(t)}{d t}=p \bar{I}_{h}-\sigma \bar{I}_{s c}(t)-\delta \bar{I}_{s c}(t)-\pi_{f} \bar{I}_{s c}(t), \\
& \frac{d \bar{C}(t)}{d t}=\delta \bar{I}_{s c}(t)+\theta(1-p) \bar{I}_{h}(t)-\gamma \bar{C}(t)-\pi_{f} \bar{C}(t), \\
& \frac{d \bar{S}_{m}(t)}{d t}=\pi_{m}-c_{m} \beta_{f} \bar{I}_{h}(t) \bar{S}_{m}(t)-\pi_{m} \bar{S}_{m}(t), \\
& \frac{d \bar{J}(t)}{d t}=c_{m} \beta_{f} \bar{I}_{h}(t) \bar{S}_{m}(t)-\zeta \bar{J}(t)-\pi_{m} \bar{J}(t) .
\end{aligned}
$$

3.2 Titik Kesetimbangan dan Angka Reproduksi Dasar

Titik kesetimbangan sistem (3) diperoleh ketika

$$
\frac{d \bar{S}_{f}(t)}{d t}=\frac{d \bar{V}(t)}{d t}=\frac{d \bar{I}_{h}(t)}{d t}=, \frac{d \bar{I}_{s c}(t)}{d t}=, \frac{d \bar{C}(t)}{d t}=, \frac{d \bar{S}_{m}(t)}{d t}=\frac{d \bar{J}(t)}{d t}=0 .
$$

Berdasarkan perhitungan analisis diperoleh dua titik kesetimbangan yaitu,

1. Titik kesetimbangan bebas penyakit

$E_{0}=\left(\bar{S}_{f}(t)^{0}, \bar{V}(t)^{0}, \bar{I}_{h}(t)^{0}, \bar{I}_{s c}(t)^{0}, \bar{C}(t)^{0}, \bar{S}_{m}(t)^{0}, \bar{J}(t)^{0}\right)=\left(\frac{\pi_{f}}{\phi+\pi_{f}}, \frac{\phi}{\phi+\pi_{f}}, 0,0,0,1,0\right)$.

Selanjutnya ditentukan angka reproduksi dasar $\left(R_{0}\right)$ yang menjadi angka penting untuk mengetahui terjadi tidaknya penyebaran penyakit pada suatu populasi. $R_{0}$ menyatakan rata-rata banyaknya individu yang terinfeksi akibat satu individu yang telah terinfeksi sebelumnya. Matriks Generasi Selanjutnya dapat digunakan untuk menentukan $R_{0}[13]$. 
Misalkan $x=\left(\bar{I}_{h}, \bar{I}_{s c}, \bar{C}, \bar{J}\right)$, maka berdasarkan model pada persamaan (3) dapat dibentuk matriks $F$ dan $V$ yang terdiri dari subpopulasi terinfeksi sebagai berikut.

$$
\frac{d x}{d t}=F(x)-V(x)
$$

dengan,

$$
F(x)=\left(\begin{array}{c}
c_{f} \beta_{m} \bar{J}(t) \bar{S}_{f}(t)+(1-\varepsilon) c_{f} \beta_{m} \bar{J}(t) \bar{V}(t) \\
0 \\
0 \\
c_{m} \beta_{f} \bar{I}_{h}(t) \bar{S}_{m}(t)
\end{array}\right),
$$

dan

$$
\mathrm{V}(\mathrm{x})=\left(\begin{array}{c}
V_{1} \\
V_{2} \\
V_{3} \\
V_{4}
\end{array}\right)=\left(\begin{array}{c}
\left(p+\pi_{f}+\theta(1-p)\right) \bar{I}_{h}(t) \\
-p \bar{I}_{h}(t)+\left(\sigma+\delta+\pi_{f}\right) \bar{I}_{s c}(t) \\
-\delta \bar{I}_{s c}(t)-\theta(1-p) \bar{I}_{h}(t)+\left(\gamma+\pi_{f}\right) \bar{C}(t) \\
\left(\zeta+\pi_{m}\right) \bar{J}(t)
\end{array}\right) .
$$

Matriks Jacobi untuk $F$ dan $V$ pada titik kesetimbangan bebas penyakit $E_{0}$ adalah sebagai berikut.

$$
\begin{aligned}
& D F\left(E_{0}\right)=\left(\begin{array}{cccc}
0 & 0 & 0 & \frac{c_{f} \beta_{m}}{\phi+\pi_{f}}\left(\pi_{f}+(1-\varepsilon) \phi\right) \\
0 & 0 & 0 & 0 \\
0 & 0 & 0 & 0 \\
c_{m} \beta_{f} & 0 & 0 & 0
\end{array}\right), \\
& D V\left(E_{0}\right)=\left(\begin{array}{cccc}
p+\pi_{f}+\theta(1-p) & 0 & 0 & 0 \\
-p & \sigma+\delta+\pi_{f} & 0 & 0 \\
-\theta(1-p) & -\delta & \gamma+\pi_{f} & 0 \\
0 & 0 & 0 & \zeta+\pi_{m}
\end{array}\right) .
\end{aligned}
$$

Selanjutnya angka reproduksi dasar $\left(R_{0}\right)$ diperoleh dari radius spectral matriks $\left(D F\left(E_{0}\right)\right)\left(D V^{-1}\left(E_{0}\right)\right)$ atau nilai eigen terbesar dari matriks $\left(D F\left(E_{0}\right)\right)\left(D V^{-1}\left(E_{0}\right)\right)$, yaitu

$$
R_{0}=\sqrt{\frac{c_{m} \beta_{f} c_{f} \beta_{m}\left(\pi_{f}+(1-\varepsilon) \phi\right)}{\left(p+\pi_{f}+\theta(1-p)\right)\left(\phi+\pi_{f}\right)\left(\zeta+\pi_{m}\right)}} .
$$

\section{Titik kesetimbangan endemi}

Titik kesetimbangan endemi $\left(E^{*}\right)$ diperoleh ketika $\bar{I}_{h}(t) \neq 0$ sehingga,

$$
E^{*}=\left(\bar{S}_{f}(t)^{*}, \bar{V}(t)^{*}, \bar{I}_{h}(t)^{*}, \bar{I}_{s c}(t)^{*}, \bar{C}(t)^{*}, \bar{S}_{m}(t)^{*}, \bar{J}(t)^{*}\right),
$$

dengan

$$
\bar{S}_{f}(t)^{*}=\frac{\pi_{f} \pi_{m}\left(\zeta+\pi_{m}\right)+\pi_{f} c_{m} \beta_{f}\left(\zeta+\pi_{m}\right) \bar{I}_{h}(t)^{*}}{\left(\phi+\pi_{f}\right)\left(\zeta \pi_{m}+\pi_{m}^{2}\right)+\left(\left(\phi+\pi_{f}\right)\left(\zeta c_{m} \beta_{f}+\pi_{m} c_{m} \beta_{f}\right)+c_{f} \beta_{m} \pi_{m} c_{m} \beta_{f}\right) \bar{I}_{h}(t)^{*}},
$$


$\bar{V}(t)^{*}=\frac{\phi \pi_{f}\left(\zeta \pi_{m}+\pi_{m}{ }^{2}+\left(\zeta c_{m} \beta_{f}+\pi_{m} c_{m} \beta_{f}\right) \bar{I}_{h}(t)^{*}\right)^{2}}{\left(\pi_{f} \pi_{m}{ }^{2}+\pi_{f} \pi_{m} \zeta+\psi_{1} \bar{I}_{h}(t)\right)\left(\pi_{m}{ }^{2} \phi+\pi_{m} \phi \zeta+\pi_{f} \pi_{m} \zeta+\pi_{f} \pi_{m}{ }^{2}+\psi_{2} \bar{I}_{h}(t)^{*}\right)^{\prime}}$

$\bar{I}_{s c}(t)^{*}=\frac{p}{\left(\sigma+\pi_{f}+\delta\right)} \bar{I}_{h}(t)^{*}$,

$\bar{C}(t)^{*}=\left[\frac{\delta p+\theta(1-p)\left(\sigma+\pi_{f}+\delta\right)}{\left(\gamma+\pi_{f}\right)\left(\sigma+\pi_{f}+\delta\right)}\right] \bar{I}_{h}(t)^{*}$,

$\bar{S}_{m}(t)^{*}=\frac{\pi_{m}}{\pi_{m}+c_{m} \beta_{f} \bar{I}_{h}(t)^{*}}$

$\bar{J}(t)^{*}=\frac{\pi_{m} c_{m} \beta_{f} \bar{I}_{h}(t)^{*}}{\left(\zeta+\pi_{m}\right)\left(\pi_{m}+c_{m} \beta_{f} \bar{I}_{h}(t)^{*}\right)}$.

$\bar{I}_{h}(t)^{*}=\frac{-q_{2}+\sqrt{q_{2}^{2}-4 q_{1} q_{3}}}{2 q_{1}}$,

dengan,

$$
\begin{aligned}
& q_{1}=\left(c_{m} \beta_{f}\right)^{2}\left[\pi_{f} \zeta+\pi_{f} \pi_{m}+\phi \zeta+\phi \pi_{m}+c_{f} \beta_{m} \pi_{m}\right]\left[\pi_{f} \zeta+\pi_{f} \pi_{m}+(1-\varepsilon) c_{f} \beta_{m} \pi_{m}\right] \\
& {\left[p+\pi_{f}+\theta(1-p)\right]>0, } \\
& q_{2}= \pi_{m} c_{m} \beta_{f}\left(\pi_{f}+\phi\right)\left(\zeta+\pi_{m}\right)\left[\pi_{f}\left(\zeta+\pi_{m}\right)+(1-\varepsilon) c_{f} \beta_{m} \pi_{m}\right]\left[p+\pi_{f}+\theta(1-p)\right] \\
&+c_{m} \beta_{f} \pi_{f} \pi_{m}\left(\zeta+\pi_{m}\right)\left[\left(\pi_{f}+\phi\right)\left(\zeta+\pi_{m}\right)+c_{f} \beta_{m} \pi_{m}\right]\left[p+\pi_{f}+\theta(1-p)\right] \\
&-\pi_{f} c_{f} \beta_{m} \pi_{m} c_{m}{ }^{2} \beta_{f}{ }^{2}\left[\pi_{f}\left(\zeta+\pi_{m}\right)+(1-\varepsilon) c_{f} \beta_{m} \pi_{m}+(1-\varepsilon) \phi\left(\zeta+\pi_{m}\right)\right], \\
& q_{3}=\pi_{m}{ }^{2} \pi_{f}\left(\zeta+\pi_{m}\right)^{2}\left(\pi_{f}+\phi\right)\left(p+\pi_{f}+\theta(1-p)\right)\left[1-R_{0}{ }^{2}\right] .
\end{aligned}
$$

Eksistensi titik kesetimbangan endemi $\left(E^{*}\right)$ bergantung pada nilai $R_{0}$. Jika $R_{0}>1$ maka diperoleh nilai $q_{3}<0$ sehingga diperoleh solusi tunggal untuk $\bar{I}_{h}(t)^{*}$ yang bernilai positif. Hal ini mengakibatkan $\bar{S}_{f}(t)^{*}, \bar{V}(t)^{*}, \bar{I}_{s c}(t)^{*}, \bar{C}(t)^{*}, \bar{S}_{m}(t)^{*}, \bar{J}(t)^{*}$ semuanya bernilai positif dan titik kesetimbangan endemi eksis.

\subsection{Kestabilan lokal titik kesetimbangan}

\subsubsection{Kestabilan Titik Kesetimbangan $\mathrm{E}_{0}$}

Kestabilan titik kesetimbangan bebas penyakit $E_{0}$ diperoleh dengan menentukan nilai eigen dari Matriks Jacobi sistem (3) ketika $E_{0}$. Titik kesetimbangan $E_{0}$ bersifat stabil asimtotik lokal jika bagian real dari nilai eigen bernilai negatif.

Matriks Jacobi di $E_{0}=\left(\frac{\pi_{f}}{\phi+\pi_{f}}, \frac{\phi}{\phi+\pi_{f}}, 0,0,0,1,0\right)$ adalah 


$$
\mathcal{J}\left(E_{0}\right)=\left[\begin{array}{ccccccc}
-\left(\phi+\pi_{f}\right) & 0 & 0 & 0 & 0 & 0 & -\frac{c_{f} \beta_{m} \pi_{f}}{\phi+\pi_{f}} \\
\phi & -\pi_{f} & 0 & 0 & 0 & 0 & -\frac{(1-\varepsilon) c_{f} \beta_{m} \phi}{\phi+\pi_{f}} \\
0 & 0 & -\left(p+\theta(1-p)+\pi_{f}\right) & 0 & 0 & 0 & \frac{c_{f} \beta_{m}}{\phi+\pi_{f}}\left(\pi_{f}+(1-\varepsilon) \phi\right) \\
0 & 0 & p & -\left(\sigma+\delta+\pi_{f}\right) & 0 & 0 & 0 \\
0 & 0 & \theta(1-p) & \delta & -\left(\gamma+\pi_{f}\right) & 0 & 0 \\
0 & 0 & -c_{m} \beta_{f} & 0 & 0 & -\pi_{m} & 0 \\
0 & 0 & c_{m} \beta_{f} & 0 & 0 & 0 & -\left(\zeta+\pi_{m}\right)
\end{array}\right]
$$

Nilai eigen dari matriks $\mathcal{J}\left(E_{0}\right)$ dapat diperoleh dengan cara menyelesaikan $\left|\mathcal{J}\left(E_{0}\right)-r I\right|=0$, sehingga diperoleh nilai eigen yaitu $r_{1}=-\pi_{f}, r_{2}=-\left(\phi+\pi_{f}\right), r_{3}=-\pi_{m}, r_{4}=-\left(\gamma+\pi_{f}\right), r_{5}=$ $-\left(\sigma+\delta+\pi_{f}\right)$ sementara $r_{6}$ dan $r_{7}$ ditentukan dengan menyelesaikan trace $(L)$ dan $|L|$, dimana

$$
L=\left(\begin{array}{cc}
-\left(p+\theta(1-p)+\pi_{f}\right) & \frac{c_{f} \beta_{m}}{\phi+\pi_{f}}\left(\pi_{f}+(1-\varepsilon) \phi\right) \\
c_{m} \beta_{f} & -\left(\zeta+\pi_{m}\right)
\end{array}\right)=0 .
$$

Dengan menggunakan metode trace dan determinan [14], diperoleh nilai $\operatorname{tr}(L)<0$ dan $|L|>0$ maka didapatkan $r_{6}<0$ dan $r_{7}<0$ jika $\sqrt{\frac{c_{m} \beta_{f} c_{f} \beta_{m}\left(\pi_{f}+(1-\varepsilon) \phi\right)}{\left(p+\pi_{f}+\theta(1-p)\right)\left(\phi+\pi_{f}\right)\left(\zeta+\pi_{m}\right)}}<1$ atau $R_{0}<1$. Oleh karena itu dapat disimpulkan bahwa titik kesetimbangan bebas penyakit $E_{0}$ bersifat stabil asimtotik lokal jika $R_{0}<1$.

\subsubsection{Kestabilan Titik Kesetimbangan $E^{*}$}

Kestabilan titik kesetimbangan bebas penyakit $E^{*}$ diperoleh dengan menentukan nilai eigen dari matriks jacobi sistem (3) ketika $E^{*}$. Titik kesetimbangan $E^{*}$ bersifat stabil asimtotik lokal jika memenuhi kriteria Routh-Hurwitz [15]. Matriks Jacobi di $E^{*}=$ $\left(\bar{S}_{f}(t)^{*}, \bar{V}(t)^{*}, \bar{I}_{h}(t)^{*}, \bar{I}_{s c}(t)^{*}, \bar{C}(t)^{*}, \bar{S}_{m}(t)^{*}, \bar{J}(t)^{*}\right)$, adalah

$$
\mathcal{J}\left(E^{*}\right)=\left[\begin{array}{ccccccc}
j_{11} & 0 & 0 & 0 & 0 & 0 & j_{17} \\
j_{21} & j_{22} & 0 & 0 & 0 & 0 & j_{27} \\
j_{31} & j_{32} & j_{33} & 0 & 0 & 0 & j_{37} \\
0 & 0 & j_{43} & j_{44} & 0 & 0 & 0 \\
0 & 0 & j_{53} & j_{54} & j_{55} & 0 & 0 \\
0 & 0 & j_{63} & 0 & 0 & j_{66} & 0 \\
0 & 0 & j_{73} & 0 & 0 & j_{76} & j_{77}
\end{array}\right],
$$

dengan,

$$
\begin{aligned}
& j_{11}=-\left(\phi+c_{f} \beta_{m} \bar{J}(t)^{*}+\pi_{f}\right), \quad j_{37}=c_{f} \beta_{m}\left(\bar{S}_{f}(t)^{*}+(1-\varepsilon) \bar{V}(t)^{*}\right), \quad j_{73}=c_{m} \beta_{f} \bar{S}_{m}(t)^{*}, \\
& j_{17}=-c_{f} \beta_{m} \bar{S}_{f}(t)^{*}, \quad j_{43}=p, \quad j_{76}=c_{m} \beta_{f} \bar{I}_{h}(t)^{*} \text {, } \\
& j_{21}=\phi, \quad j_{44}=-\left(\sigma+\delta+\pi_{f}\right), \quad j_{77}=-\left(\zeta+\pi_{m}\right) \text {. } \\
& j_{22}=-\left((1-\varepsilon) c_{f} \beta_{m} \bar{J}(t)^{*}+\pi_{f}\right), \quad j_{53}=\theta(1-p), \\
& j_{27}=-(1-\varepsilon) c_{f} \beta_{m} \bar{V}(t)^{*}, \quad j_{54}=\delta,
\end{aligned}
$$




$$
\begin{array}{ll}
j_{31}=c_{f} \beta_{m} \bar{J}(t)^{*}, & j_{55}=-\left(\gamma+\pi_{f}\right), \\
j_{32}=(1-\varepsilon) c_{f} \beta_{m} \bar{J}(t)^{*}, & j_{63}=-c_{m} \beta_{f} \bar{S}_{m}(t)^{*}, \\
j_{33}=-\left(p+\theta(1-p)+\pi_{f}\right), & j_{66}=-\left(c_{m} \beta_{f} \bar{I}_{h}(t)^{*}+\pi_{m}\right),
\end{array}
$$

Nilai eigen dari matriks $\mathcal{J}\left(E^{*}\right)$ dapat diperoleh dengan cara menyelesaikan $\left|\mathcal{J}\left(E^{*}\right)-r I\right|=0$, sehingga diperoleh nilai eigen yaitu $r_{1}=-\left(\gamma+\pi_{f}\right), r_{2}=-\left(\sigma+\delta+\pi_{f}\right)$, dan $|G|=0$, dengan

$$
|G|=\left|\begin{array}{ccccc}
j_{11}-r & 0 & 0 & 0 & j_{17} \\
j_{21} & j_{22}-r & 0 & 0 & j_{27} \\
j_{31} & j_{32} & j_{33}-r & 0 & j_{37} \\
0 & 0 & j_{63} & j_{66}-r & 0 \\
0 & 0 & j_{73} & j_{76} & j_{77}-r
\end{array}\right|,
$$

memenuhi kriteria Routh-Hurwitz. Dari perhitungan $|G|=0$ maka didapatkan persamaan karakteristik sebagai berikut.

$$
r^{5}+a_{1} r^{4}+a_{2} r^{3}+a_{3} r^{2}+a_{4} r+a_{5}=0
$$

dengan

$$
\begin{aligned}
a_{1}= & 2 \pi_{m}+3 \pi_{f}+c_{m} \beta_{f} \bar{I}_{h}^{*}(t)+\zeta+\phi+p+\theta(1-p)+c_{f} \beta_{m} \bar{J}^{*}(t)+(1-\varepsilon) c_{f} \beta_{m} \bar{J}^{*}(t), \\
a_{2}= & \left(\zeta+\pi_{m}+\phi+c_{f} \beta_{m} \bar{J}^{*}(t)+3 \pi_{f}+p+\theta(1-p)+(1-\varepsilon) c_{f} \beta_{m} \bar{J}^{*}(t)\right)\left(c_{m} \beta_{f} \bar{I}_{h}^{*}(t)+\pi_{m}\right) \\
& +\left(\phi+c_{f} \beta_{m} \bar{J}^{*}(t)+3 \pi_{f}+p+\theta(1-p)+(1-\varepsilon) c_{f} \beta_{m} \bar{J}^{*}(t)\right)\left(\zeta+\pi_{m}\right) \\
& +\left(\phi+c_{f} \beta_{m} \bar{J}^{*}(t)+\pi_{f}\right)\left(p+\theta(1-p)+2 \pi_{f}+(1-\varepsilon) c_{f} \beta_{m} \bar{J}^{*}(t)\right) \\
& +\left(p+\theta(1-p)+\pi_{f}\right)\left((1-\varepsilon) c_{f} \beta_{m} \bar{J}^{*}(t)+\pi_{f}\right) \\
& +\left(c_{m} \beta_{f} \bar{S}_{m}^{*}(t)\right)\left(c_{f} \beta_{m}\left(\bar{S}_{f}^{*}(t)+(1-\varepsilon) \bar{V}^{*}(t)\right)\right) \\
a_{3}= & \left(\zeta+\pi_{m}\right)\left(c_{m} \beta_{f} \bar{I}_{h}^{*}(t)+\pi_{m}\right)\left(\phi+c_{f} \beta_{m} \bar{J}^{*}(t)+3 \pi_{f}+p+\theta(1-p)+(1-\varepsilon) c_{f} \beta_{m} \bar{J}^{*}(t)\right) \\
& +\left(\phi+c_{f} \beta_{m} \bar{J}^{*}(t)+\pi_{f}\right)\left(c_{m} \beta_{f} \bar{I}_{h}^{*}(t)+\pi_{m}\right)\left(p+\theta(1-p)+2 \pi_{f}+(1-\varepsilon) c_{f} \beta_{m} \bar{J}^{*}(t)\right) \\
& +\left(p+\theta(1-p)+\pi_{f}\right)\left((1-\varepsilon) c_{f} \beta_{m} \bar{J}^{*}(t)+\pi_{f}\right)\left(c_{m} \beta_{f} \bar{I}_{h}^{*}(t)+\pi_{m}\right) \\
& +\left(\zeta+\pi_{m}\right)\left(p+\theta(1-p)+\pi_{f}\right)\left(\phi+c_{f} \beta_{m} \bar{J}^{*}(t)+2 \pi_{f}+(1-\varepsilon) c_{f} \beta_{m} \bar{J}^{*}(t)\right) \\
& +\left(\phi+c_{f} \beta_{m} \bar{J}^{*}(t)+\pi_{f}\right)\left((1-\varepsilon) c_{f} \beta_{m} \bar{J}^{*}(t)+\pi_{f}\right)\left(\zeta+\pi_{m}+p+\theta(1-p)+\pi_{f}\right) \\
& +\left(c_{m} \beta_{f} \bar{S}_{m}^{*}(t)\right)\left(2 \pi_{f} c_{f} \beta_{m} \bar{S}_{f}^{*}(t)+(1-\varepsilon) c_{f}{ }^{2} \beta_{m}{ }^{2} \bar{J}^{*}(t)\left(\bar{S}_{f}^{*}(t)+\bar{V}^{*}(t)\right)\right. \\
& \left.+c_{f} \beta_{m} \bar{S}_{f}^{*}(t) \phi+2 \pi_{f}(1-\varepsilon) c_{f} \beta_{m} \bar{V}^{*}(t)+(1-\varepsilon) \phi c_{f} \beta_{m} \bar{V}^{*}(t)\right) \\
& +c_{m} \beta_{f} \bar{S}_{m}^{*}(t) \pi_{m} c_{f} \beta_{m}\left(\bar{S}_{f}^{*}(t)+(1-\varepsilon) \bar{V}^{*}(t)\right),
\end{aligned}
$$




$$
\begin{aligned}
a_{4}= & \left(\zeta c_{m} \beta_{f} \bar{I}_{h}^{*}(t)+\zeta \pi_{m}+\pi_{m} c_{m} \beta_{f} \bar{I}_{h}^{*}(t)+\pi_{m}{ }^{2}\right)\left(\left(\phi+c_{f} \beta_{m} \bar{J}^{*}(t)+\pi_{f}\right)\right. \\
& \left(p+\theta(1-p)+2 \pi_{f}+(1-\varepsilon) c_{f} \beta_{m} \bar{J}^{*}(t)\right)+\left(p+\theta(1-p)+\pi_{f}\right) \\
& \left((1-\varepsilon) c_{f} \beta_{m} \bar{J}^{*}(t)+\pi_{f}\right)+\left(\phi+c_{f} \beta_{m} \bar{J}^{*}(t)+\pi_{f}\right)\left(p+\theta(1-p)+\pi_{f}\right) \\
& \left((1-\varepsilon) c_{f} \beta_{m} \bar{J}^{*}(t)+\pi_{f}\right)\left(c_{m} \beta_{f} \bar{I}_{h}^{*}(t)+2 \pi_{m}+\zeta\right)+c_{m} \beta_{f} \bar{S}_{m}^{*}(t)\left(2 c_{f} \beta_{m} \bar{S}_{f}^{*}(t) \pi_{m} \pi_{f}\right. \\
+ & (1-\varepsilon) c_{f}{ }^{2} \beta_{m}{ }^{2} \bar{S}_{f}^{*}(t) \bar{J}^{*}(t) \pi_{m}+c_{f} \beta_{m} \bar{S}_{f}^{*}(t) \pi_{m} \phi \\
+ & 2(1-\varepsilon) c_{f} \beta_{m} \bar{V}^{*}(t) \pi_{m} \pi_{f}+(1-\varepsilon) c_{f} \beta_{m} \bar{V}^{*}(t) \pi_{m} \phi \\
+ & (1-\varepsilon) c_{f}{ }^{2} \beta_{m}{ }^{2} \bar{V}^{*}(t) \pi_{m} \bar{J}^{*}(t)+\phi \pi_{f} c_{f} \beta_{m} \bar{S}_{f}^{*}(t)+(1-\varepsilon) c_{f} \beta_{m} \bar{V}^{*}(t) \phi \pi_{f} \\
+ & (1-\varepsilon) \pi_{f} c_{f}{ }^{2} \beta_{m}{ }^{2} \bar{J}^{*}(t) \bar{V}^{*}(t)+(1-\varepsilon)^{2} c_{f}{ }^{3} \beta_{m}{ }^{3} \bar{J}^{*}(t)^{2} \bar{V}^{*}(t) \\
+ & \left.\pi_{f}{ }^{2} c_{f} \beta_{m} \bar{S}_{f}^{*}(t)+\pi_{f}{ }^{2}(1-\varepsilon) c_{f} \beta_{m} \bar{V}^{*}(t)+\pi_{f}(1-\varepsilon) c_{f}{ }^{2} \beta_{m}{ }^{2} \bar{J}^{*}(t) \bar{S}_{f}^{*}(t)\right) . \\
a_{5}= & \pi_{m} c_{m} \beta_{f} \bar{S}_{m}^{*}(t)\left(\phi \pi_{f} c_{f} \beta_{m} \bar{S}_{f}^{*}(t)+\phi \pi_{f}(1-\varepsilon) c_{f} \beta_{m} \bar{V}^{*}(t)+\pi_{f}(1-\varepsilon) c_{f}{ }^{2} \beta_{m}{ }^{2} \bar{J}^{*}(t) \bar{V}^{*}(t)\right. \\
& \left.+\pi_{f}{ }^{2} c_{f} \beta_{m} \bar{S}_{f}^{*}(t)+\pi_{f}{ }^{2}(1-\varepsilon) c_{f} \beta_{m} \bar{V}^{*}(t)+\pi_{f}(1-\varepsilon) c_{f}{ }^{2} \beta_{m}{ }^{2} \bar{J}^{*}(t) \bar{S}_{f}^{*}(t)\right) \\
& +\left(\phi+c_{f} \beta_{m} \bar{J}^{*}(t)+\pi_{f}\right)\left(p+\theta(1-p)+\pi_{f}\right)\left((1-\varepsilon) c_{f} \beta_{m} \bar{J}^{*}(t)+\pi_{f}\right) \\
& \left(\zeta+\pi_{m}\right)\left(c_{m} \beta_{f} \bar{I}_{h}^{*}(t)+\pi_{m}\right),
\end{aligned}
$$

Berdasarkan kriteria Routh Hurwitz akar-akar persamaan karakteristik (4) memiliki bagian real negatif karena memenuhi kriteria sebagai berikut.

1. $a_{1}=2 \pi_{m}+3 \pi_{f}+c_{m} \beta_{f} \bar{I}_{h}^{*}(t)+\zeta+\phi+p+\theta(1-p)+c_{f} \beta_{m} \bar{J}^{*}(t)+(1-\varepsilon) c_{f} \beta_{m} \bar{J}^{*}(t)>0$,

$$
\begin{aligned}
a_{5}= & \pi_{m} c_{m} \beta_{f} \bar{S}_{m}^{*}(t)\left(\phi \pi_{f} c_{f} \beta_{m} \bar{S}_{f}^{*}(t)+\phi \pi_{f}(1-\varepsilon) c_{f} \beta_{m} \bar{V}^{*}(t)+\pi_{f}(1-\varepsilon) c_{f}{ }^{2} \beta_{m}{ }^{2} \bar{J}^{*}(t) \bar{V}^{*}(t)\right. \\
& \left.+\pi_{f}{ }^{2} c_{f} \beta_{m} \bar{S}_{f}^{*}(t)+\pi_{f}{ }^{2}(1-\varepsilon) c_{f} \beta_{m} \bar{V}^{*}(t)+\pi_{f}(1-\varepsilon) c_{f}{ }^{2} \beta_{m}{ }^{2} \bar{J}^{*}(t) \bar{S}_{f}^{*}(t)\right) \\
& +\left(\phi+c_{f} \beta_{m} \bar{J}^{*}(t)+\pi_{f}\right)\left(p+\theta(1-p)+\pi_{f}\right)\left((1-\varepsilon) c_{f} \beta_{m} \bar{J}^{*}(t)+\pi_{f}\right)\left(\zeta+\pi_{m}\right)\left(c_{m} \beta_{f} \bar{I}_{h}^{*}(t)+\pi_{m}\right)>0,
\end{aligned}
$$

2. $a_{1} a_{2}-a_{3}=\left(c_{m} \beta_{f} \bar{I}_{h}^{*}(t)+\pi_{m}\right)^{2}\left(\zeta+\pi_{m}+\phi+c_{f} \beta_{m} \bar{J}^{*}(t)+3 \pi_{f}+p+\theta(1-p)+(1-\varepsilon) c_{f} \beta_{m} \bar{J}^{*}(t)\right)$

$$
\begin{aligned}
& +2\left(\zeta+\pi_{m}\right)\left(c_{m} \beta_{f} \bar{I}_{h}^{*}(t)+\pi_{m}\right)\left(\phi+c_{f} \beta_{m} \bar{J}^{*}(t)+3 \pi_{f}+p+\theta(1-p)+(1-\varepsilon) c_{f} \beta_{m} \bar{J}^{*}(t)\right) \\
& +2\left(\phi+c_{f} \beta_{m} \bar{J}^{*}(t)+\pi_{f}\right)\left(c_{m} \beta_{f} \bar{I}_{h}^{*}(t)+\pi_{m}\right)\left(p+\theta(1-p)+2 \pi_{f}+(1-\varepsilon) c_{f} \beta_{m} \bar{J}^{*}(t)\right) \\
& +2\left(p+\theta(1-p)+\pi_{f}\right)\left((1-\varepsilon) c_{f} \beta_{m} \bar{J}^{*}(t)+\pi_{f}\right)\left(c_{m} \beta_{f} \bar{I}_{h}^{*}(t)+2 \pi_{m}+\zeta+\phi+c_{f} \beta_{m} \bar{J}^{*}(t)+\pi_{f}\right) \\
& +\left(\zeta+\pi_{m}\right)^{2}\left(c_{m} \beta_{f} \bar{I}_{h}^{*}(t)+\pi_{m}+\phi+c_{f} \beta_{m} \bar{J}^{*}(t)+3 \pi_{f}+p+\theta(1-p)+(1-\varepsilon) c_{f} \beta_{m} \bar{J}^{*}(t)\right) \\
& +c_{m} \beta_{f} \bar{S}_{m}^{*}(t)\left(c_{f} \beta_{m}\left(\bar{S}_{f}^{*}(t)+(1-\varepsilon) \bar{V}^{*}(t)\right)\right)\left(\zeta+\pi_{m}+p+\theta(1-p)+\pi_{f}+c_{m} \beta_{f} \bar{I}_{h}^{*}(t)\right) \\
& +\left(\phi+c_{f} \beta_{m} \bar{J}^{*}(t)+\pi_{f}\right)^{2}\left(c_{m} \beta_{f} \bar{I}_{h}^{*}(t)+2 \pi_{m}+\zeta+p+\theta(1-p)+2 \pi_{f}+(1-\varepsilon) c_{f} \beta_{m} \bar{J}^{*}(t)\right) \\
& +2\left(\phi+c_{f} \beta_{m} \bar{J}^{*}(t)+\pi_{f}\right)\left(\zeta+\pi_{m}\right)\left(p+\theta(1-p)+2 \pi_{f}+(1-\varepsilon) c_{f} \beta_{m} \bar{J}^{*}(t)\right) \\
& +\left(p+\theta(1-p)+\pi_{f}\right)^{2}\left(c_{m} \beta_{f} \bar{I}_{h}^{*}(t)+2 \pi_{m}+\zeta+\phi+c_{f} \beta_{m} \bar{J}^{*}(t)+2 \pi_{f}+(1-\varepsilon) c_{f} \beta_{m} \bar{J}^{*}(t)\right) \\
& +\left((1-\varepsilon) c_{f} \beta_{m} \bar{J}^{*}(t)+\pi_{f}\right)^{2}\left(c_{m} \beta_{f} \bar{I}_{h}^{*}(t)+2 \pi_{m}+\zeta+\phi+c_{f} \beta_{m} \bar{J}^{*}(t)+2 \pi_{f}+p+\theta(1-p)\right) \\
& +c_{m} \beta_{f} c_{f}^{2} \beta_{m}{ }^{2} \bar{S}_{m}^{*}(t) \bar{J}^{*}(t)\left(\bar{S}_{f}^{*}(t)+(1-\varepsilon)^{2} \bar{V}^{*}(t)\right)>0
\end{aligned}
$$

3. $a_{1} a_{2} a_{3}+a_{1} a_{5}-a_{3}{ }^{2}-a_{1}{ }^{2} a_{4}>0$,

4. $a_{1} a_{2} a_{3} a_{4}+2 a_{1} a_{4} a_{5}+a_{2} a_{3} a_{5}-a_{1}^{2} a_{4}^{2}-a_{1} a_{2}^{2} a_{5}-a_{3}^{2} a_{4}-a_{5}^{2}>0$. 
Kriteria (1) dan (2) telah terpenuhi dengan detail perhitungan yang telah dijabarkan. Dengan demikian, titik kesetimbangan endemi $E^{*}$ stabil asimtotik lokal jika memenuhi kriteria (3) dan (4) yang dibuktikan secara numerik.

\subsection{Simulasi Numerik}

Pada bagian ini dilakukan simulasi numerik untuk mengilustrasikan kestabilan titik kesetimbangan bebas penyakit $E_{0}$ ketika $R_{0}<1$ dan juga dilakukan simulasi numerik untuk mengilustrasikan kestabilan titik kesetimbangan endemi $E^{*}$ ketika $R_{0}>1$. Simulasi numerik dilakukan untuk mendukung hasil analisis yang telah diperoleh. Nilai awal yang digunakan adalah $\bar{S}_{f}(0)=0.3, \bar{V}(0)=0.2, \bar{I}_{h}(0)=0.1, \bar{I}_{s c}(0)=0.1, \bar{C}(0)=0.2, \bar{S}_{m}(0)=0.5, \bar{J}(0)=0.3$, dan nilai parameter yang digunakan pada simulasi ini tercantum pada Tabel 2.

Tabel 2. Nilai parameter untuk simulasi numerik

\begin{tabular}{ccc}
\hline Parameter & $\begin{array}{c}\text { Nilai Parameter } \\
\text { Simulasi } R_{0}<1\end{array}$ & $\begin{array}{c}\text { Nilai Parameter } \\
\text { Simulasi } R_{0}>1\end{array}$ \\
\hline$\pi_{f}\left(\pi_{m}\right)$ & 0.5 & 0.5 \\
$\beta_{f}\left(\beta_{m}\right)$ & 0.4 & 0.8 \\
$c_{f}\left(c_{m}\right)$ & 2 & 3 \\
$\phi$ & 0.05 & 0.05 \\
$\varepsilon$ & 0.95 & 0.95 \\
$p$ & 0.01 & 0.01 \\
$\theta$ & 0.1 & 0.1 \\
$\sigma$ & 0.7 & 0.7 \\
$\zeta$ & 0.7 & 0.7 \\
$\delta$ & 0.05 & 0.05 \\
$\gamma$ & 0.01 & 0.01 \\
\hline
\end{tabular}

\subsubsection{Simulasi I: Kestabilan titik $E_{0}$ saat $R_{0}<1$}

Pada simulasi ini digunakan nilai parameter seperti pada Tabel 2 dengan $\beta_{f}=0.4, \beta_{m}=$ $0.4, c_{f}=2$, dan $c_{m}=2$, sehingga didapatkan nilai $R_{0}=0.8945<1$.

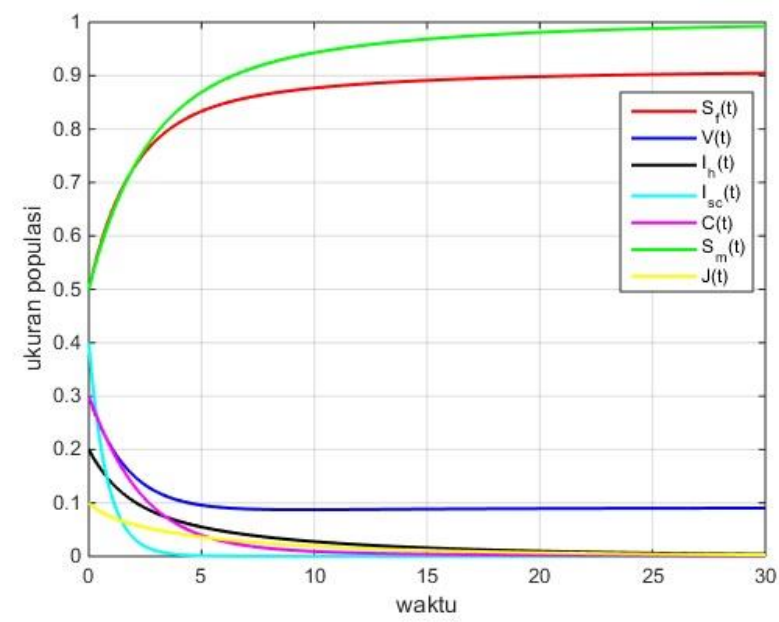

Gambar 2. Solusi numerik kestabilan $E_{0}$ saat $R_{0}=0.8945<1$ 
Berdasarkan Gambar 2 ditunjukkan bahwa solusi numerik konvergen menuju titik kesetimbangan $E_{0}\left(\bar{S}_{f}, \bar{V}, \bar{I}_{h}, \bar{I}_{s c}, \bar{C}, \bar{S}_{m}, \bar{J}\right)=(0.9091,0.0909,0,0,0,1,0)$. Hasil simulasi tersebut sesuai dengan hasil analisis yang diperoleh bahwa jika $R_{0}<1$ tidak ada infeksi pada subpopulasi dan titik kesetimbangan bebas penyakit $E_{0}$ bersifat stabil asimtotik.

\subsubsection{Simulasi I: Kestabilan titik $E^{*}$ saat $R_{0}>1$}

Pada simulasi ini digunakan nilai parameter seperti pada Tabel 2 dengan $\beta_{f}=0.8, \beta_{m}=$ $0.8, c_{f}=3$, dan $c_{m}=3$, sehingga didapatkan nilai $R_{0}=2.6835>1$.

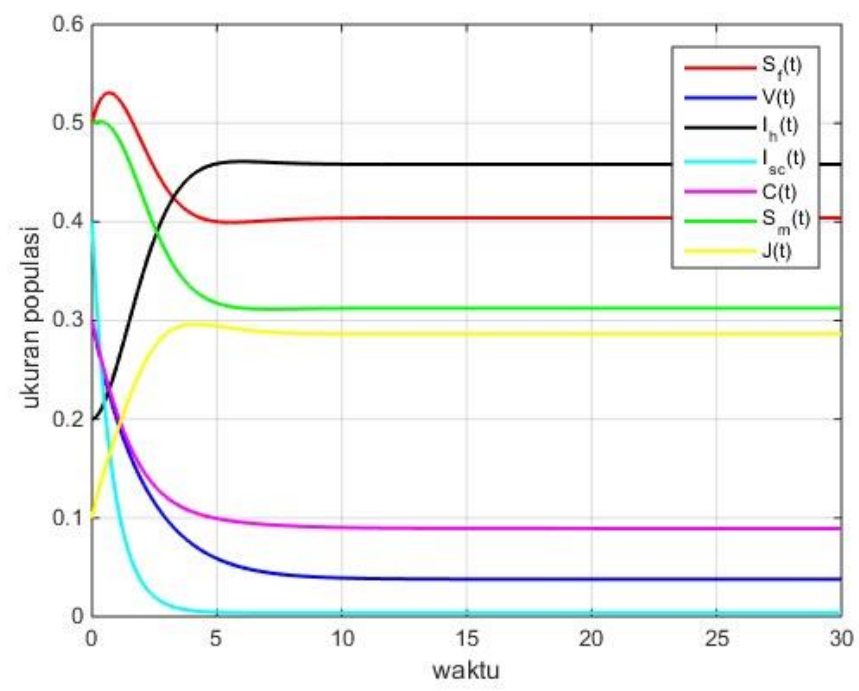

Gambar 3. Solusi numerik kestabilan $E^{*}$ saat $R_{0}=2.6835<1$

Berdasarkan Gambar 3 ditunjukkan bahwa solusi numerik konvergen menuju titik kesetimbangan $E^{*}\left(\bar{S}_{f}, \bar{V}, \bar{I}_{h}, \bar{I}_{s c}, \bar{C}, \bar{S}_{m}, \bar{J}\right)=(0.4041,0.0516,0.4583,0.0037,0.0893,0.3125,0.2864)$. Sementara itu juga diperoleh nilai $a_{1} a_{2} a_{3}+a_{1} a_{5}-a_{3}{ }^{2}-a_{1}{ }^{2} a_{4}=337.7289>0$ dan $a_{1} a_{2} a_{3} a_{4}+$ $2 a_{1} a_{4} a_{5}+a_{2} a_{3} a_{5}-a_{1}{ }^{2} a_{4}{ }^{2}-a_{1} a_{2}{ }^{2} a_{5}-a_{3}{ }^{2} a_{4}-a_{5}{ }^{2}=1481.8>0$ sehingga kriteria RouthHurwitz terpenuhi. Dengan demikian titik kesetimbangan $E^{*}$ bersifat stabil asimtotik lokal. Oleh karena itu dapat disimpulkan bahwa hasil simulasi sesuai dengan hasil analisis yang diperoleh bahwa jika $R_{0}>1$ maka terjadi penyebaran infeksi pada subpopulasi dan titik kesetimbangan endemi $E^{*}$ bersifat stabil asimtotik. 


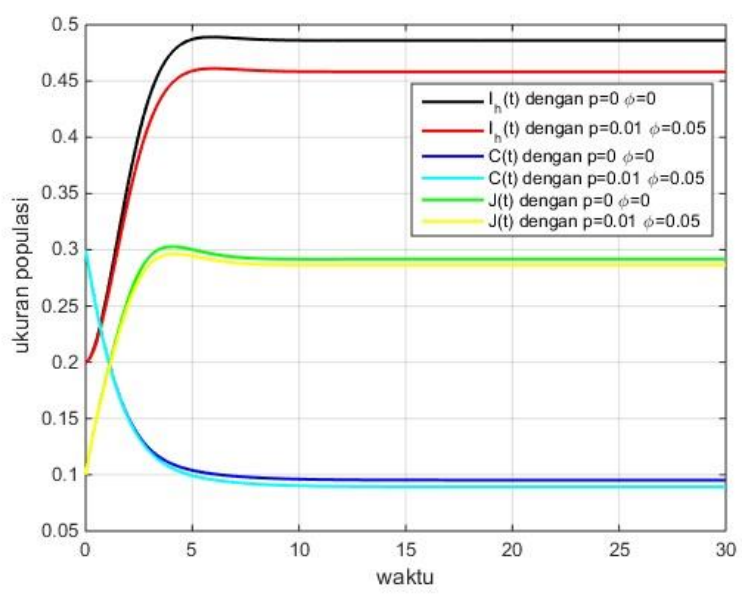

Gambar 4. Grafik solusi jumlah subpopulasi terinfeksi saat $p=0, \phi=0, p=0.01, \phi=0.05$

Gambar 4 menunjukkan pengaruh tidak dan adanya pemberian vaksinasi maupun screening terhadap jumlah subpopulasi wanita terinfeksi $\left(\bar{I}_{h}\right)$, subpopulasi wanita terkena kanker serviks $(\bar{C})$, dan subpopulasi pria terinfeksi $(\bar{J})$. Parameter $p=0, \phi=0$ menunjukkan tidak ada tindakan vaksinasi dan screening yang diberikan. Pada Gambar 4 terlihat bahwa pemberian vaksinasi dan screening dengan parameter $p=0.01, \phi=0.05$ mampu mengurangi jumlah subpopulasi terinfeksi diantaranya mengurangi jumlah subpopulasi wanita terinfeksi HPV, subpopulasi wanita terkena kanker serviks, dan subpopulasi pria terinfeksi HPV.

\section{Simpulan}

Berdasarkan hasil pembahasan pada penelitian ini, maka dapat disimpulkan sebagai berikut.

- Model penyebaran kanker serviks dengan vaksinasi dan screening mempunyai dua titik kesetimbangan. Titik kesetimbangan tersebut yaitu titik kesetimbangan bebas penyakit dan titik kesetimbangan endemi. Eksistensi dan kestabilan titik kesetimbangan bergantung pada nilai angka reproduksi dasar $R_{0}$. Titik kesetimbangan bebas penyakit eksis tanpa syarat dan titik kesetimbangan endemi eksis jika $R_{0}>1$. Titik kesetimbangan bebas penyakit bersifat stabil asimtotik lokal jika nilai $R_{0}<1$ dan titik kesetimbangan endemi bersifat stabil asimtotik lokal karena memenuhi kriteria Routh-Hurwitz.

- Pemberian vaksinasi dan screening memiliki pengaruh untuk mengurangi jumlah subpopulasi terinfeksi.

- Simulasi numerik yang dilakukan mendukung hasil analisis dinamik yang diperoleh. 


\section{$5 \quad$ Daftar Pustaka}

[1] M. Nenad dan M. Olivera, What Every Woman Should Know about Cervical Cancer. Springer, 2001.

[2] F.X. Bosch, N. Munoz,dkk.,"Risk factors for cervical cancer in Colombia and Spain,"Journal of cancer 52, pp. 750-758,1992.

[3] World Health Organization(WHO), Human Papillomavirus (HPV) and Cervical cancer. Diakses 12 Februari 2020, http://www.who.int/mediacentre/factsheets/fs380/en/_2016.

[4] T. Malik ,M. Imran, dan R. Jayaraman, "Optimal Control with Multiple Human Papillomavirus," Journal of Theoretical Biology 393, pp. 179-193, 2016.

[5] O. Sharomi dan T. Malik, "A model to assess the effect of vaccine compliance on Human Papillomavirus infection and cervical cancer," Applied Mathematical Modelling 47, pp. $528-550,2017$.

[6] I. Rasjidi, "Epidemiologi Kanker Serviks," Indonesian Journal of Cancer 3, pp. 103108,2009 .

[7] E.H. Elbasha, "Impact of Prophylactic Vaccination Againts Human Papillomavirus Infection," Contempory Mathematics 410, pp. 113-127,2006.

[8] L. Majed dan R. Lounes, "A SIS Model for Human Papillomavirus Transmission," HAL archives-ouvertes 3, pp.15-23,2011.

[9] N. Van de Velde, M. Boily, M. D. Franco, E. Mayrand, dkk., "Population Level Impact of The Bivalent, Quadrivalent, and Nonavalent Human Papillomavirus Vaccines," Journal of Cancer 104, pp. 1712-1723, 2012.

[10] F. A. Saldana, I. Korobeinikov, dan Barradas, "Optimal Control Againts The Human Papillomavirus Protection Versus Eradication of The Infection," Abstract and Applied Analysis 10, pp. 1-13,2019.

[11] Hasnawati, R. ratianingsih, dan J.W Puspita, "Analisis Kestabilan Model Matematika dan Penyebaran Kanker Serviks Menggunakan Kriteria Routh-Hurwitz," Jurnal Ilmiah Matematika dan Terapan 14, pp. 120-127, 2017.

[12] N. Puspitasari, Y. A. Adi, dan R.S. Winanda, "Analisis Kestabilan Lokal pada Model Matematika Kanker Serviks Akibat Human Papillomavirus," Jurnal Ilmu Alam dan Teknologi Terapan, vol.1, no. 1, pp. 115-125, 2019.

[13] F. Brauer dan C.C. Carlos, "Mathematical Models in Population Biology and Epidemiology,". Springer, 2010.

[14] A. Panfilov, Qualitative Analysis of Differential Equations. Theoretical Biology,2004. 
[15] J. D. Murray, Mathematical Biology : An Introduction. Springer, 2002. 